\title{
DEVELOPMENT OF CATABOLIC PATHWAYS IN INSECT FLIGHT MUSCLES. A COMPARATIVE STUDY
}

\author{
A. M. Th. BEENAKKERS, A. Th. M. VAN DEN BROEK, and \\ TH. J. A. DE RONDE \\ Laboratory of Chemical Animal Physiology, The State University of Utrecht, \\ Transitorium III, 8 Padualaan, Utrecht, The Netherlands
}

(Received 2 September 1974; revised 10 October 1974)

\begin{abstract}
Activities of enzymes representative of glycolytic and $\beta$-oxidative pathways and citric acid and glycerophosphate cycles were measured in the developing flight muscles of three species: Calliphora erythrocephala, Locusta migratoria, and Philosamia cynthia. The activities were measured in vitro under optimal conditions.

The enzyme pattern of young flight muscles is quite different from the adult pattern. In the second half of the developmental period final differentiation towards the adult metabolic pattern takes place, in Calliphora leading to exclusively carbohydrate-oxidizing capacities, in Locusta to properties enabling both aerobic glycolytic and $\beta$-oxidative processes, whereas Philosamia becomes oriented to fatty acid oxidation. This differentiation starts after a temporary rise of lactate dehydrogenase activity, a phenomenon that seems to be connected with invagination of tracheoblasts into the muscle fibres. This tracheolization might be necessary for differentiation towards the species specific metabolic properties of the adult flight muscle.

Theoretical aspects of the enzyme activities, as they were measured in the in vitro assays, are discussed and related to the physiological qualities of the flight muscles of the three species investigated.
\end{abstract}

\section{INTRODUCTION}

CARBoHYdRates and fatty acids play a predominant rôle in the generation of energy for prolonged flights in insects (BEENAKKERS, 1969; SACKTOR, 1970). Participation of amino acids in catabolic pathways of flight muscles has been demonstrated in some insect species (SACKTOR and Childress, 1967; Stevenson, 1968; DE KorT et al., 1973), but it has not been proved that they contribute directly to the energy supply for continued flight; proline, for instance, might enhance the rate of pyruvate metabolism in flight muscles of Phormia regina by raising the mitochondrial concentration of citric acid cycle intermediates (SACKTOR and CHILDRESS, 1967).

It is generally agreed that three physiological types of insect flight muscles can be distinguished: carbohydrate utilizers, lipid utilizers, and combination utilizers (BEENAKKERS, 1969). BEENAKKERS (1969) investigated the catabolic properties of 
the dorsal longitudinal flight muscles of nine insect species belonging to four different orders by measuring enzyme activities of the glycolytic chain, the $\beta$-oxidative pathway, and the citric acid cycle and showed among others that the flight muscles of Apis mellifica (Hym.) are specialized for carbohydrate oxidation, those of Philosamia cynthia (Lep.) for fatty acid oxidation, whereas the flight muscles of Locusta migratoria (Orth.) can use both carbohydrates and fatty acids. As far as investigated, most Diptera are dependent on carbohydrates during flight (Drosophila, Wigglesworth, 1949; Phaenica, Yurkiewicz and Mathur, 1969; Aedes, Nayar and van Handel, 1971).

The final characteristics of the adult flight muscles must be obtained during the structural and functional development of the growing muscles. BEENAKKERS (1963, 1964) measured the activities of some catabolic enzymes during the development of locust flight muscles. In an elaborate study BRoSEMER et al. (1963) investigated the development of subcellular structures together with enzymatic properties in the flight muscles of the same insect.

In endopterygote insects data about muscle development are mainly restricted to structural studies. HeROLD (1965) investigated sarcosomal development in the honey-bee flight muscle; NüESCH (1965) connected structural development of flight muscles of Antheraea with the functional appearance of actomyosine. Electron microscopic studies of flight muscle development in Calliphora were made by Auber (1969) and in Lucilia by Peristianis and Gregory (1971).

The present study deals with the differentiation of enzyme activities in developing flight muscles of Philosamia cynthia, and Calliphora erythrocephala, (which in preliminary experiments turned out to be a carbohydrate utilizer) in comparison with Locusta migratoria.

Insects

\section{MATERIALS AND METHODS}

Migratory locusts, L. migratoria, were reared in our laboratory under crowded conditions. Within $24 \mathrm{hr}$ after the fourth ecdysis the larvae were collected and kept under crowded conditions at $30^{\circ} \mathrm{C}$, r.h. of about $40 \%$, and with a photoperiod of $12 \mathrm{hr}$. They were fed with reed or with equal parts of wheat and rye-leaves, supplemented with rolled oats. Under these conditions the fifth instar period lasts 9 days.

P. cynthia was reared at $24^{\circ} \mathrm{C}$, r.h. of $50 \%$, and with a $12 \mathrm{hr}$ photoperiod. Egg development lasted 12 days; then after about 30 days the larvae started spinning the cocoon and generally 4 days later larval-pupal ecdysis took place. Eighteen days after the ecdysis the adult emerged. The larvae were fed with privet leaves.

The blowfly C. erythrocephala was reared at $25^{\circ} \mathrm{C}$ and a daily illumination of $16 \mathrm{hr}$. Ovoposition took place on rumpsteak, and egg development was completed within $24 \mathrm{hr}$. After a developmental period of 6 to 7 days on rumpsteak, the larvae were starved for the next 2 days; then pupariation followed. One day after pupariation the animals were collected. Further development until adult emergence lasted 10 to 11 days. The adults were fed with water and a mixture of sucrose and yeast flakes $(3: 1, \mathrm{w} / \mathrm{w})$. 


\section{Preparation of the fight muscles}

In the locust, already on the day following the last larval ecdysis distinct flight muscles can be distinguished. On several days during fifth instar and adult development the dorsal longitudinal flight muscles were dissected out and placed in $3 \mathrm{ml} 0 \cdot 1 \mathrm{M}$ potassium phosphate buffer, containing $2 \mathrm{mM}$ sodium EDTA ( $\mathrm{pH} \mathrm{7.3)}$, kept on ice. In each experiment about 100 mg muscle (fresh weight) was used.

On several days between the larval-pupal and pupal-adult ecdysis and after adult emergence, flight muscles of the mesothoracic segment of Philosamia were collected. Particularly during the first days after larval-pupal ecdysis the dorsal flight muscles cannot be exactly separated from the fat body and other tissues in the thorax, and therefore contamination with non-muscular material occurs. About 60 to $80 \mathrm{mg}$ of the collected material was placed in the buffer mentioned above.

In Calliphora dissection of the flight muscles was practically impossible, therefore about 20 thoraces were collected on several days after pupariation up to and including the first day after emergence of the adult. With a double scalpel the thoracic part of the insect was cut out. After adult ecdysis, the thoracic appendages and the head were cut off and the abdomen and gut were removed. Particularly during pupal and pharate adult development the flight muscles were contaminated with non-muscular material.

The collected muscles were disrupted with an ultra-Turrax disintegrator (JankeKunkel). The suspension was stirred for 30 minutes with a magnetic stirrer and then centrifuged $(20,000 \mathrm{~g}$ for $15 \mathrm{~min})$. The residue was resuspended in $3 \mathrm{ml}$ of fresh K-phosphate buffer. The extract and the resuspended sediment were separately assayed for enzyme activities. All manipulations with the dissected muscles until measurement of the enzyme activities were carried out at 0 to $2^{\circ} \mathrm{C}$.

\section{Estimation of enzyme activities}

Activities were estimated photometrically at $25^{\circ} \mathrm{C}$, using a photometer with automatic recording of absorption against time. The following activities were measured: glyceraldehydephosphate dehydrogenase (E.C. 1.2.1.12; GAPDH), lactate dehydrogenase (E.C. 1.1.1.27; LDH), glycerophosphate dehydrogenase (E.C. 1.1.1.8; GDH), 3-hydroxyacyl-CoA dehydrogenase (E.C. 1.1.1.35; HOAD), citrate synthase (E.C. 4.1.3.7; CS), and succinate dehydrogenase (E.C. 1.3.99.1; $\mathrm{SDH})$ The assay mixtures are described in BEENAKKERS (1969).

\section{Protein determinations}

Protein was determined according to LowRY et al. (1951), using a bovine albumin solution as a standard.

\section{RESULTS}

As discussed earlier (BEENAKKERs, 1969), it is possible to evaluate the rôle of a particular enzyme in the metabolic system by comparing the activities of that enzyme in different tissues, for instance various muscles or, in the scope of the present investigation, on different developmental days of a certain organ. The 
852 A. M. Th. Beenakkers, A. Th. M. Van Den Broek, and Th. J. A. De Ronde

enzymes were chosen in such a way that participation of the main catabolic processes, important for energy generation, could be estimated. Moreover by comparing the ratios of enzymes belonging to different pathways, information about their quantitative significance for metabolism in various muscles can be obtained (PETT'E, 1965).

TABle 1-Relation of ENZYMe aCtivities IN THE DEVELOPING FLIGHT MUSCLES OF THE BLOWFLY, C. erythrocephala*

\begin{tabular}{|c|c|c|c|c|c|c|}
\hline & \multicolumn{6}{|c|}{ Age } \\
\hline & \multicolumn{5}{|c|}{ Days after pupariation } & \multirow{2}{*}{$\begin{array}{c}\begin{array}{c}\text { Day after } \\
\text { adult } \\
\text { emergence }\end{array} \\
1\end{array}$} \\
\hline & 2 & 4 & 6 & 8 & 10 & \\
\hline \multicolumn{7}{|l|}{ Glycolytic chain } \\
\hline GAPDH & 46,100 & 31,400 & 46,900 & 69,500 & 114,400 & 194,500 \\
\hline $\mathrm{LDH}$ & 13,900 & 7400 & 9700 & 4500 & 2800 & $<50$ \\
\hline \multicolumn{7}{|c|}{ Glycerophosphate cycle } \\
\hline $\mathrm{GDH}$ & 70 & $<50$ & $<50$ & 340 & 11,900 & 48,300 \\
\hline \multicolumn{7}{|l|}{$\beta$-oxidative pathway } \\
\hline HOAD & 4800 & 2300 & 4000 & 4200 & 2200 & $<50$ \\
\hline \multicolumn{7}{|l|}{ Citric acid cycle } \\
\hline CS & 2200 & 1700 & 2350 & 9900 & 23,800 & 45,200 \\
\hline \multicolumn{7}{|l|}{ Ratio: } \\
\hline GAPDH/GDH & & & & 205 & 10 & 4 \\
\hline GAPDH/HOAD & 10 & 14 & 12 & 16 & 52 & $>1000$ \\
\hline GAPDH/CS & 21 & 18 & 20 & 7 & 5 & 4 \\
\hline $\mathrm{HOAD} / \mathrm{CS}$ & $2 \cdot 2$ & $1 \cdot 3$ & $1 \cdot 7$ & 0.4 & $0 \cdot 1$ & $\rightarrow 0$ \\
\hline
\end{tabular}

* Activities expressed as $\mu$ moles/g tissue protein per hour. Each value represents the mean of a least 5 experiments.

Table 1 summarizes data on the activities of the enzymes measured in the blowfly. During the first 6 days of development flight muscles show relatively low $\mathrm{CS}$ activities and high $\mathrm{LDH}$ activities. In the second half-period metabolism becomes highly aerobic, as CS activity increases considerably and the activity of $\mathrm{LDH}$ drops to very low values. Together with a rise in glycolytic capacity the glycerophosphate cycle becomes very important, as shown by an enormous increase in GDH activity ( $c f$. the ratio GAPDH/GDH). As particularly in experiments with animals shortly after pupariation contamination with other thoracic tissues will be substantial, it is not clear whether the muscles themselves ever had 
$\beta$-oxidative capacity. But at any rate the decreasing activities of HOAD indicate a decrease in fatty acid oxidation. In the adult, flight muscle metabolism is confined to aerobic breakdown of carbohydrate; the ratio GAPDH/CS is four and the ratio $\mathrm{HOAD} / \mathrm{CS}$ approximates zero.

'TABLE 2-RELATION OF ENZYME ACTIVITIES IN THE DEVELOPING FLIGHT MUSCLES OF THE мотн, $P$. cynthia*

\begin{tabular}{|c|c|c|c|c|c|c|c|}
\hline & \multicolumn{7}{|c|}{ Developmental day after } \\
\hline & \multicolumn{5}{|c|}{ Larval-pupal ecdysis } & \multicolumn{2}{|c|}{ Adult emergence } \\
\hline & 4 & 7 & 10 & 12 & 17 & 3 & 5 \\
\hline \multicolumn{8}{|l|}{ Glycolytic chain } \\
\hline $\begin{array}{l}\text { GAPDH } \\
\mathrm{LDH}\end{array}$ & $\begin{array}{r}25,100 \\
1590\end{array}$ & $\begin{array}{r}15,000 \\
2400\end{array}$ & $\begin{array}{r}14,900 \\
4100\end{array}$ & $\begin{array}{r}16,000 \\
6000\end{array}$ & $\begin{array}{r}19,700 \\
2800\end{array}$ & $\begin{array}{r}17,600 \\
1300\end{array}$ & $\begin{array}{r}18,100 \\
600\end{array}$ \\
\hline \multicolumn{8}{|c|}{ Glycerophosphate cycle } \\
\hline GDH & 7600 & 3700 & 2300 & 2100 & 4500 & 11,100 & 12,740 \\
\hline \multicolumn{8}{|l|}{$\beta$-oxidative pathway } \\
\hline HOAD & 3800 & 3600 & & 10,300 & 66,000 & 82,000 & 98,000 \\
\hline \multicolumn{8}{|l|}{ Citric acid cycle } \\
\hline $\begin{array}{l}\mathrm{CS} \\
\mathrm{SDH}\end{array}$ & $\begin{array}{l}1600 \\
<50\end{array}$ & $\begin{array}{l}1800 \\
<50\end{array}$ & & $\begin{array}{r}3700 \\
170\end{array}$ & $\begin{array}{r}43,000 \\
1900\end{array}$ & $\begin{array}{r}71,000 \\
3600\end{array}$ & $\begin{array}{r}80,500 \\
4200\end{array}$ \\
\hline \multicolumn{8}{|l|}{ Ratio: } \\
\hline $\begin{array}{l}\text { GAPDH/GDH } \\
\text { GAPDH/HOAD } \\
\text { GAPDH/CS } \\
\text { HOAD/CS } \\
\text { CS/SDH }\end{array}$ & $\begin{array}{l}3 \cdot 3 \\
6 \cdot 6 \\
1 \cdot 6 \\
2 \cdot 4\end{array}$ & $\begin{array}{l}4 \cdot 1 \\
4 \cdot 2 \\
8 \cdot 3 \\
2 \cdot 0\end{array}$ & $6 \cdot 5$ & $\begin{array}{l}7 \cdot 6 \\
1 \cdot 6 \\
4 \cdot 3 \\
2 \cdot 8 \\
22\end{array}$ & $\begin{array}{l}4 \cdot 4 \\
0 \cdot 3 \\
0 \cdot 5 \\
1 \cdot 5 \\
23\end{array}$ & $\begin{array}{r}1 \cdot 6 \\
0 \cdot 2 \\
0 \cdot 2 \\
1 \cdot \\
20\end{array}$ & $\begin{array}{l}1 \cdot 4 \\
0 \cdot 2 \\
0 \cdot 2 \\
1 \cdot 2 \\
19\end{array}$ \\
\hline
\end{tabular}

* Activities expressed as $\mu$ moles/g protein per hour. Each value represents the mean of at least 5 experiments.

Table 2 gives the activity data in the flight muscles of $P$. cynthia. With respect to our experimental data the following phenomena during development are most important. GAPDH activity remains practically unchanged; the initial higher value on the fourth day after larval-pupal ecdysis could be caused by contamination with non-muscular material. During the first developmental period the activity of HOAD is low, but around day 12 its specific activity increases considerably which is continued until day 5 of the adult life. The activity of CS follows the same trend. LDH activity is increasing up to the twelfth day after larval-pupal ecdysis and then decreases considerably. GDH activity is acting in the opposite 


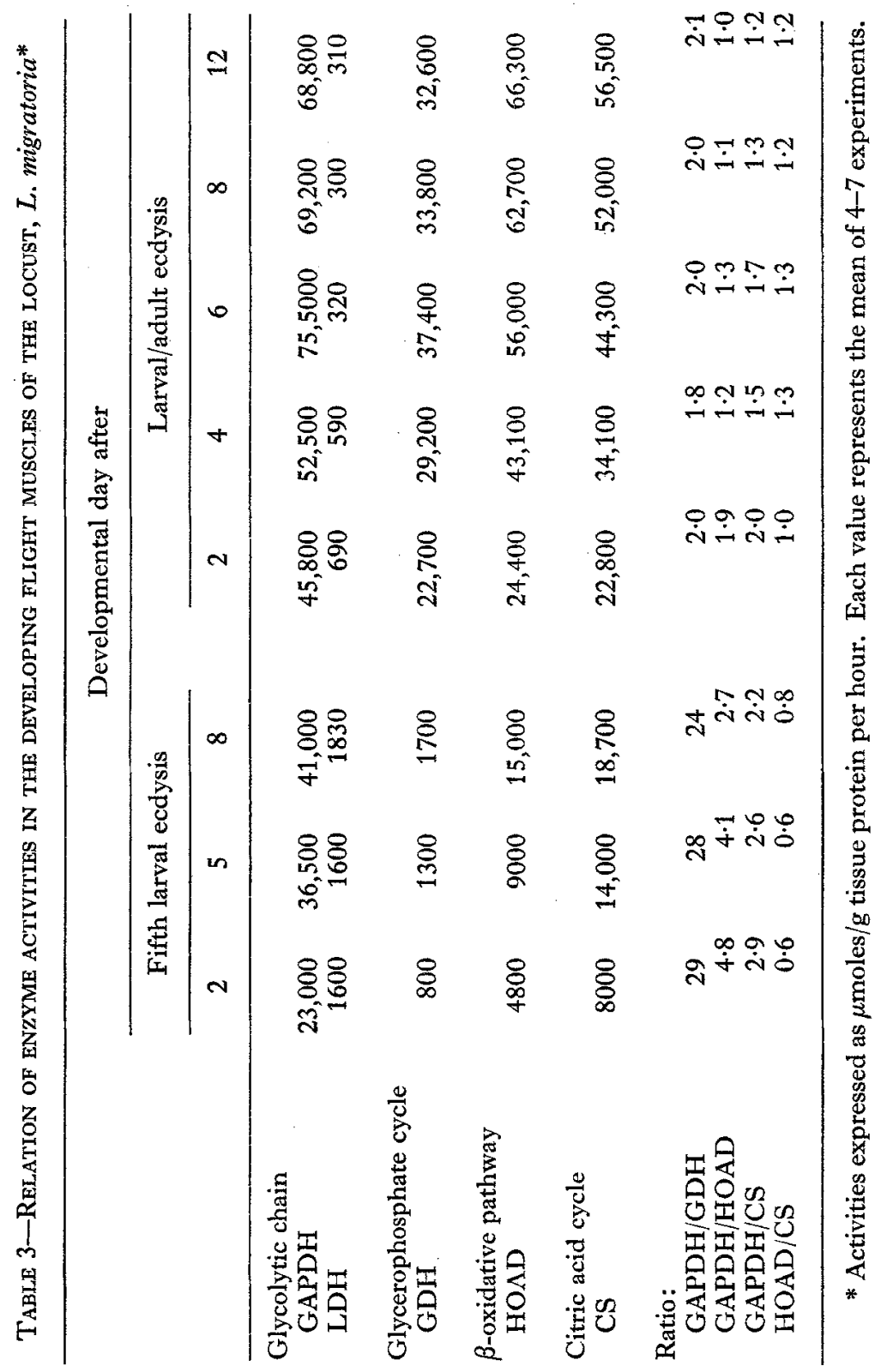


way, emphasizing an anaerobic period in about the middle of the total developmental period. Comparison of the ratios GAPDH/HOAD on the various developmental days reveals that during development the flight muscles become oriented to fatty acid oxidation which is also to be seen from the final ratio GAPDH/CS being $0 \cdot 2$, and the reduction of the ratio $\mathrm{HOAD} / \mathrm{CS}$ to 1.2 during the second half period of development. From the day that SDH activity was definitely measurable with our assay, a virtually constant proportion to CS activity exists, indicating a concomitant rise in citric acid cycle enzymes. The ratio between these two enzymes is almost identical with that found in the flight muscles of several other insects (BEENAKKERS, 1969).

The enzyme activities in the flight muscles of the locust are shown in Table 3. During the fifth instar, in the beginning of which flight muscle development starts, the metabolic pattern is different from that after adult ecdysis. GDH activity is low but increases considerably during the moulting period; LDH activity, on the contrary, remains relatively high until ecdysis, whereupon its specific activity decreases. In the first week of development the activity of CS is higher than in the muscles of both other insects during a corresponding period; this could mean that the metabolism has more aerobic properties. After adult ecdysis the specific activity of CS increases strongly. This is accompanied by a substantial rise of HOAD activity; its increase exceeds that of CS, as is visible also from the changes in the $\mathrm{HOAD} / \mathrm{CS}$ ratio. Contrary to the situation in the blowfly $\mathrm{GAPDH} / \mathrm{CS}$ ratio in the adult locust muscle is only 1.2 ; the $\mathrm{HOAD} / \mathrm{CS}$ ratio equals that in the moth.

There is a striking phenomenon, present in the development of the flight muscles of the three species examined: at about the middle of the developmental period, $\mathrm{LDH}$ activity reaches a relatively high value. For reasons discussed later, in Fig. 1 the activities of the enzymes on the various developmental days were plotted in relation to the activity of the respective enzymes on the day of maximal LDH activity. It seems quite pertinent that this day is a decisive day in development; from this day on a definite course leading to the ultimate metabolic pattern is taken. Aerobic pathways become more pronounced, not only the citric acid cycle, but also the glycerophosphate cycle, important for reoxidation of cytoplasmic NADH originating from carbohydrate oxidation. In Calliphora $\beta$-oxidation becomes unimportant. In Philosamia the metabolic pattern is definitely driven to fatty acid oxidation; the glycolytic pathway is unaffected. In Locusta the activity of this pathway is still increasing after the reference day, and $\beta$-oxidation becomes relatively more and more important.

\section{DISCUSSION}

In order to evaluate activity changes during the development of the flight muscles and to compare enzyme patterns in the various developmental stages, we must keep in mind that particularly in early development other material than flight muscles will be present in thoracic preparations, at least in the two endopterygote 


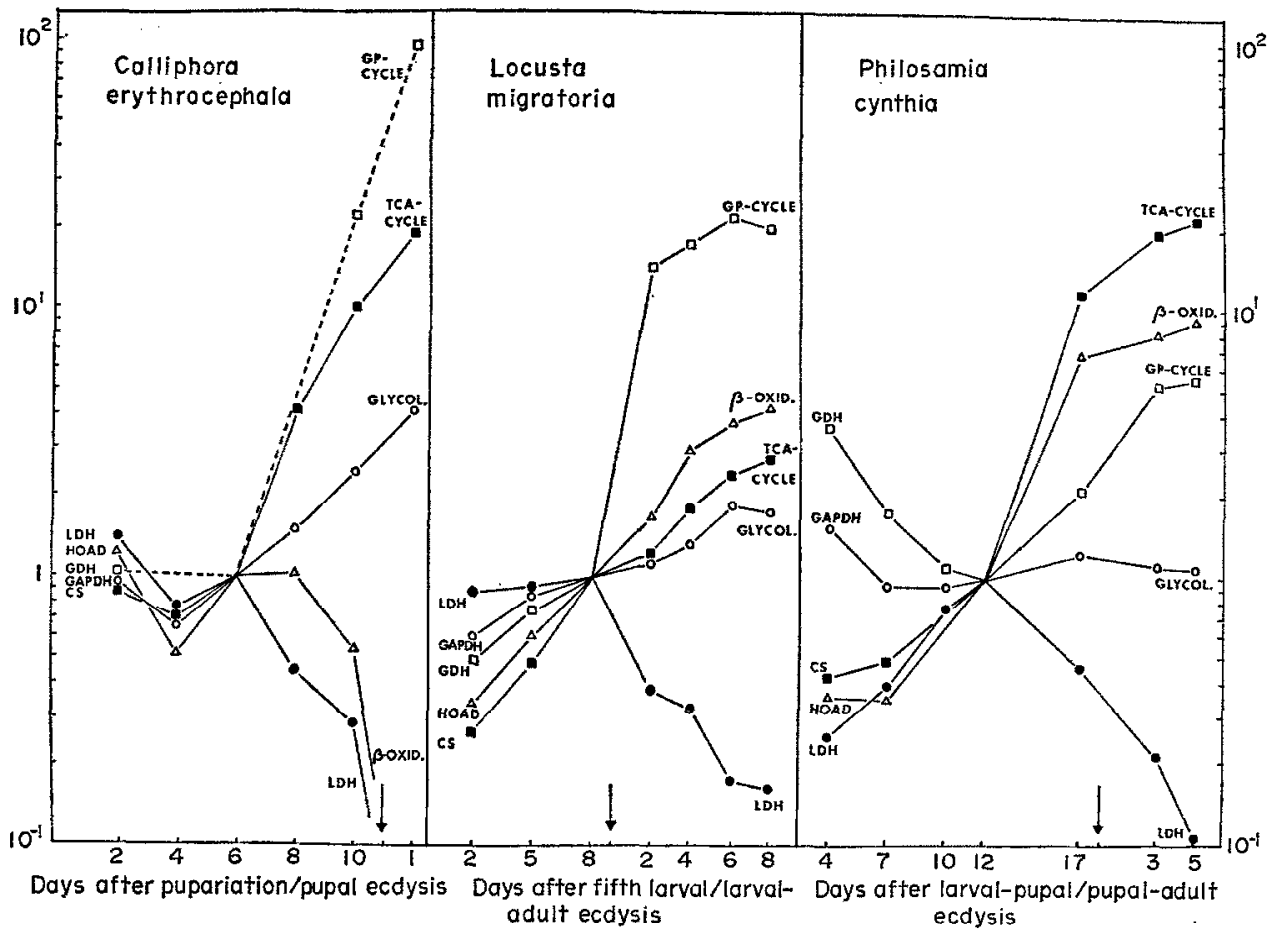

FIG. 1. Development of the main catabolic pathways in the flight muscles of three insect species. The activities of the enzymes at the indicated developmental days are related to the activity of the respective enzyme at the day of maximal lactate dehydrogenase activity. Related activities are plotted in a logarithmic scale. On the left side of each drawing the actually measured enzymes are given, on the right side the pathway they represent. Arrows indicate the moment of adult emergence. (For abbreviations see Materials and Methods; GP cycle, glycerophosphate cycle).

insects. We therefore started our experiments not before the second day after pupariation in C. erythrocephala and day 4 after larval-pupal ecdysis in P. cynthia. In the latter insect flight muscles were dissected out as well as possible. In another lepidopteran, Antheraea, NüEsch (1965) showed that already at day 3 muscle fibres of the adult muscles are present. In the blowfly Lucilia cuprina, PERIsTIanis and GREgory (1971) demonstrated that at the first day after puparium formation the development of the dorsal longitudinal flight muscles starts by longitudinal cleavage of two sets of three larval muscles in which neighbouring myoblasts are incorporated. In C. erythrocephala AUBER (1969) also saw larval muscles taking part in the development of adult flight muscles.

So, although certainly some products of histolytical processes will have been present in early pupal preparations, it seems quite certain that a substantial part of it was muscular tissuc, quickly increasing later. These considerations and the forcgoing data lead us to state that the various developmental stages of the flight 
muscles of the insects investigated show their own characteristic set of enzyme activities. The ultimate enzyme pattern is different from the pattern in earlier stages, at least up to a certain developmental level. Not only the specific activities of the enzymes are different, but also the ratios between the enzymes. In P. cynthia the final pattern is reached shortly after imaginal ecdysis and the maximum catabolic activity around day 3 of emerged adult life. In the locust the definite enzyme pattern is present in the 8-day-old emerged adult, although some activity ratios, for instance GAPDH/GDH and HOAD/CS, become 'final' some days earlier. The most profound changes take place in the period between the last day before and 4 days after adult ecdysis. This is in accordance with the findings of BROSEMER et al. (1963) that in Locusta during the first days of emerged adult life differentiation of the typical adult flight muscle characteristics occurs. In $C$. erythrocephala the enzyme pattern in the flight muscles of the first-day-emerged adult may not be the ultimate pattern. AUBER (1969) showed that the number of filaments in the myofibrils increases till day 10, but any profound change in enzyme ratios is not to be expected, although the specific activities of glycolytic and citric acid cycle enzymes may still increase after day 1 . The enzyme ratios in the flight muscles of the adult honey-bee, also a carbohydrate utilizer, are almost identical with those of the blowfly on the first day after adult emergence (BEENAKKERS, 1969). The most pronounced changes are observed 6 days after pupariation; from that day on metabolism is drastically turned over to oxidative carbohydrate breakdown.

For all three muscle types examined it is clear that essential changes in the metabolic pattern of the developing flight muscles take place after the temporary rise in LDH activity, i.e. at day 6 after puparium formation in Calliphora, 12 days after larval-pupal ecdysis in Philosamia and at the day of larval adult ecdysis in the locust. For the last-named insect BROSEMER et al. (1963) have correlated the rise in $\mathrm{LDH}$ activity with the invagination of tracheoblasts into the muscle fibre, a phenomenon consequently taking place after larval-adult apolysis. Differentiation of locust flight muscles succeeds this tracheolization. Also in the two endopterygote insects investigated, the moment of maximum LDH activity seems to be some kind of turning point, a decisive point for further development towards the adult metabolic pattern. As was visualized in Fig. 1 from that moment on the definite course to final metabolic properties is taken, both with respect to the aerobic nature as to the kind of substrate(s) used for energetic purpose. If it is true that also in Calliphora and Philosamia the temporary rise in $\mathrm{LDH}$ activity reflects tracheoblast invagination, it might be assumed that this phenomenon necessarily precedes final development of the flight muscle. As far as we are aware, no data are available to confirm this in Lepidoptera. In another blowfly, Lucilia, in which adult emergence takes place $7 \frac{1}{2}$ days after pupariation, Peristianis and GREGORY (1971) demonstrated penetration of tracheoblasts into the muscle fibres at day $3 \frac{1}{2}$ to $4 \frac{1}{2}$. These time relations are in good agreement with our enzymatic findings in Calliphora. WoLFE (1954) stated that in C. erythrocephala pupal-adult apolysis takes place at $c a .80 \mathrm{hr}$ after pupariation, which indicates that also in this inscct trachcolization occurs after adult apolysis as in the locust. Of course, our findings do not allow any 
causal relation to be predicted between these time-sequential processes; it should be merely used as a working hypothesis.

There is another point that ought to receive some attention. PETTE (1965) discussed the significance of enzyme ratios, as presented in the tables, in giving information about the quantitative importance of a certain pathway in the specific metabolism of a particular tissue (the so-called correlation of systems). Table 4

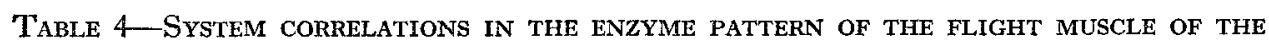
INSECTS

\begin{tabular}{lccc}
\hline & C. erythrocephala & L. migratoria & P. cynthia \\
\hline$\frac{\text { Glycolysis }}{\beta \text {-Oxidation }}:$ GAPDH/HOAD & $>1000$ & $1 \cdot 0$ & 0.2 \\
$\frac{\text { Glycolysis }}{\text { Citric acid cycle }}:$ GAPDH/CS & 4 & 1.2 & 0.2 \\
$\frac{\beta \text {-Oxidation }}{\text { Citric acid cycle }}:$ HOAD/CS & $\rightarrow 0$ & $1 \cdot 2$ & 1.2 \\
\hline
\end{tabular}

summarizes the main system correlations in the adult flight muscles of the three insects investigated. It must be emphasized that we are dealing here with obligatory aerobic muscles. As already discussed, the GAPDH/HOAD ratio indicates the relative importance of the two major substrates for energy generation.

We may assume that the activity of the citric acid cycle is related to the energy demand of the adult flight muscle. This implies that for optimal use of this cycle the activities of the preceding pathways, glycolysis and $\beta$-oxidation, must meet its activity. In normal in vivo situations a $1: 1$ ratio between each of the supplying pathways and the Krebs cycle is supposed. In our in vitro measurements, under optimal activity conditions, a deviating value could be expected. As the blowfly is an exclusively carbohydrate utilizer the GAPDII/CS ratio will be representative for an optimal relation between the pathways to which they belong. Hence it follows (Table 4) that in order to obtain a maximum of energy from the oxidation of carbohydrates, i.e. to ensure an efficient supply of acetyl-CoA to the citric acid cycle, under the conditions used in the in vitro assays the enzyme activity of GAPDH must be four times that of CS. This value is in good accordance with the GAPDH/ CS ratio of 4.5 in the brain tissue of the rat (PETTE, 1965). If in some tissue fatty acid oxidation is the exclusive pathway, as in $P$. cynthia flight muscles during continued flight, the data in Table 4 predict the activity of HOAD to be 1.2 times that of CS. If we consider the enzyme ratios from locust flight muscles in the light of these figures it is evident that fatty acid oxidation can meet the energy demands of intense flight, but carbohydrate oxidation, however, cannot, which 
supports the idea that carbohydrates are used in raising thoracic temperature, during first flight activities or in periods of relatively low wing-beat frequencies.

The GAPDH/CS ratio of 0.2 in Philosamia suggests that glycolysis, although being of little, if any, value for direct energy supply, might have some significance for flight. This suggestion is supported by the fact that in the second half of development the activity of the glycerophosphate cycle, represented by GDH, increases. It seems possible that glycolytic activities are meant for the supply of citric acid cycle intermediates, a suggestion that was made earlier by STEVENSON (1968) in discussing the results of experiments on carbohydrate metabolism in Prodenia eridania.

\section{REFERENCES}

Auber J. (1969) I a myofihrillngenèse du muscle strié. I. Insectes. F. Microscopie 8, 197-232. Beenakkers A. M. Th. (1963) Enzyme der Fettsäure-Oxydation in den Flugmuskeln von Locusta migratoria während ihrer Entwicklung. Biochem. Z. 337, 436-439.

BeEnakkers A. M. TH. (1964) Vetzuuroxidatie in de vliegspieren van Locusta migratoria. Thesis, Utrecht.

BeENAKrKers A. M. Th. (1969) Carbohydrate and fat as a fuel for insect flight. A comparative study. F. Insect Physiol. 15, 353-361.

Brosemer R. W., Vogell W., and Bücher T. (1963) Morphologische und enzymatische Muster bei der Entwicklung indirekter Flugmuskeln von Locusta migratoria. Biochem. Z. 338, 854-910.

Herold R. C. (1965) Development and ultrastructural changes of sarcosomes during honeybee flight muscle development. Devel. Biol. 12, 269-286.

DE KORT C. A. D., Bartelink A. K. M., and Schudrman R. R. (1973) The significance of L-proline for oxidative metabolism in the flight muscles of the colorado beetle, Leptinotarsa decemlineata. Insect Biochem. 3, 11-17.

Lowry O. H., Rosebrough N. J., Farr A. L., and Randall R. J. (1951) Protein measurement with the Folin phenol reagent. F. biol. Chem. 193, 265-275.

NAYAR J. K. and vaN HANDEL E. (1971) The fuel for sustained mosquito flight. $\mathcal{F}$. Insect Physiol. 17, 471-481.

NüESCH H. (1965) Ueber die strukturelle un funktionelle Entwicklung der Muskeln bei Antheraea (Lepidoptera). Z. Naturf. 20b, 343-347.

Peristianis S. C. and Gregory D. W. (1971) Early stages of flight muscle development in the blowfly Lucilia cuprina: a light and electron microscopic study. F. Insect Physiol. 17, $1005-1022$.

Pette D. (1965) Plan und Muster im zellulären Stoffwechsel. Naturwissenschaften 22, $597-616$.

SACKTOR B. (1970) Regulation of intermediary metabolism, with special reference to the control mechanisms in insect flight muscle. Adv. Insect Physiol. 7, 267-347.

SACKTor B. and Childress C. C. (1967) Metabolism of proline an insect flight muscle and its significance in stimulating the oxidation of pyruvate. Archs Biochim. Biophys. 120, $583-588$.

STEvenson E. (1968) Carbohydrate metabolism in the flight muscle of the Southern Army moth, Prodenia eridania. F. Insect Physiol. 14, 179-198.

WigGlesworth V. B. (1949) The utilization of reserve substances in Drosophila during flight. F. exp. Biol. 26, 150-163.

WOLFE L. S. (1954) Studies of the development of the imaginal cuticle of Calliphora erythrocephala. Quart. F. micr. Sci.95, 67-78.

YURKIEWICZ W. J. and MATHUR C. F. (1969) Incorporation of palmitate-1-C ${ }^{14}$ into lipids of the blowfly during flight. F. Insect Physiol. 15, 439-444. 